\title{
Voltammetric Detection of Oxalic Acid by Using Glassy Carbon Electrodes with Covalently Attached Nitrogen-containing Functional Groups
}

\author{
Hiroaki Matsudra, $* * * *$ Syuhei Akabe,* Tsubasa Kitamura,* Takuto TaKahaShi,* and \\ Shunichi UCHIYAMA* \\ *Department of Applied Chemistry, Graduate School of Engineering, Saitama Institute of Technology, \\ 1690 Fusaiji, Fukaya, Saitama 369-0293, Japan \\ **Department of Life Science \& Green Chemistry, Faculty of Engineering, Saitama Institute of Technology, \\ 1690 Fusaiji, Fukaya, Saitama 369-0293, Japan
}

\begin{abstract}
We report on a novel voltammetric detection of oxalic acid by using glassy carbon electrodes with covalently attached nitrogen-containing functional groups prepared by stepwise electrolysis. A glassy carbon electrode electrooxidized in an ammonium carbamate solution was electroreduced at $-1.0 \mathrm{~V}(v s . \mathrm{Ag} / \mathrm{AgCl})$ in $1.0 \mathrm{M}$ sulfuric acid for a long time. We found that the electrocatalytic oxidation wave of oxalic acid obtained by this modified glassy carbon electrode was moved to a more negative potential region than that obtained by a platinum electrode in an acidic medium. A good linearity for the peak current signals was observed in the concentration range from 0.1 to $50 \mathrm{mM}$.
\end{abstract}

Keywords Electrocatalytic oxidation, oxalic acid, voltammetric detection, glassy carbon electrode

(Received February 23, 2015; Accepted March 3, 2015; Published July 10, 2015)

\section{Introduction}

Oxalic acid contained in various plants (spinach, nuts, chocolate, etc.) can combine with calcium $(\mathrm{Ca})$ or potassium $(\mathrm{K})$ to form poorly soluble salts known as oxalates. High concentration levels of these salts in meal can lead to a disorder of the digestive tract of the stomach and kidneys. It is also known to contribute to the formation of kidney stones. The level of oxalic acid in urine has been recognized as an important marker for the diagnosis of renal stone formation. Several techniques for measuring oxalic acid, such as spectrophotometric, ${ }^{1}$ highperformance liquid chromatographic, ${ }^{2}$ and enzymatic methods, ${ }^{3}$ have been reported. However, these methods have often suffered from various disadvantages concerning expensive, troublesome, and time-consuming sample detection. The electroanalysis of oxalic acid using some metal electrodes, such as platinum or gold, has been proposed. ${ }^{4-6}$ On the other hand, there are very few papers concerning the electrochemical oxidation of oxalic acid at a carbon-based electrode, such as highly boron-doped diamond (BDD) electrodes, ${ }^{7}$ and palladium-modified glassy carbon electrodes. ${ }^{8}$

Carbon electrodes have been widely used in electroanalysis due to a wide potential window, a low background current and chemical inertness as compared with metal electrodes.9-11 Moreover, the chemical modification of carbon surfaces has been of significant interest in numerous fields, such as electroanalytical chemistry. ${ }^{12,13}$ It has recently been found that the reduction potential of oxygen can be significantly moved the positive direction by using a carbon alloy with nitrogen ${ }^{14}$ and nitrogen-containing graphite. ${ }^{15}$ In particular, it has been revealed by us that nitrogen-containing functional groups, such as an amino group, can easily be introduced to the surfaces of a glassy carbon (GC) electrode by the electrode oxidation of ammonium carbamate. ${ }^{16}$ We named this electrooxidized GC electrode as an aminated GC electrode. In this modification process, not only the primary amine group (i.e., aniline-like aromatic amine moiety) but also other $\mathrm{N}$-containing functional groups (i.e., the secondary amine-like moieties containing pyrrole-type nitrogen and quaternary amine-like moieties containing graphitic quaternary nitrogen) can be introduced onto the GC electrode surface. ${ }^{17}$ More recently, we obtained very interesting results concerning novel redox waves between hydrogen ions and hydrogen molecules $\left(\mathrm{H}_{2}\right)$ appearing at a highly positive potential range after long-term electrode reduction of the aminated GC electrode in a strong acid electrolyte. We named this electroreduced-aminated GC electrode as a N-containing functional groups introduced glassy carbon (NF-GC) electrode. In addition, we reported that the $\mathrm{H}_{2}$ redox wave that appeared is related to the mutual redox reactions between the hydrazino, diazene and diazo groups bonded to the electrode surface. ${ }^{18}$ Moreover, the electrocatalytic activity for the electrode oxidation of $\mathrm{H}_{2}$ has been successfully applied to the coulometric determination of the dissolved hydrogen. ${ }^{19}$

In this study, we intend to describe that the electrocatalytic oxidation wave of oxalic acid can be observed by using NF-GC electrodes fabricated by the electrode reduction of an aminated $\mathrm{GC}$ electrode in a sulfuric acid electrolyte. In addition, the NF$\mathrm{GC}$ electrodes have been used for the voltammetric detection of oxalic acid.

† To whom correspondence should be addressed.

E-mail: matsuura@sit.ac.jp 


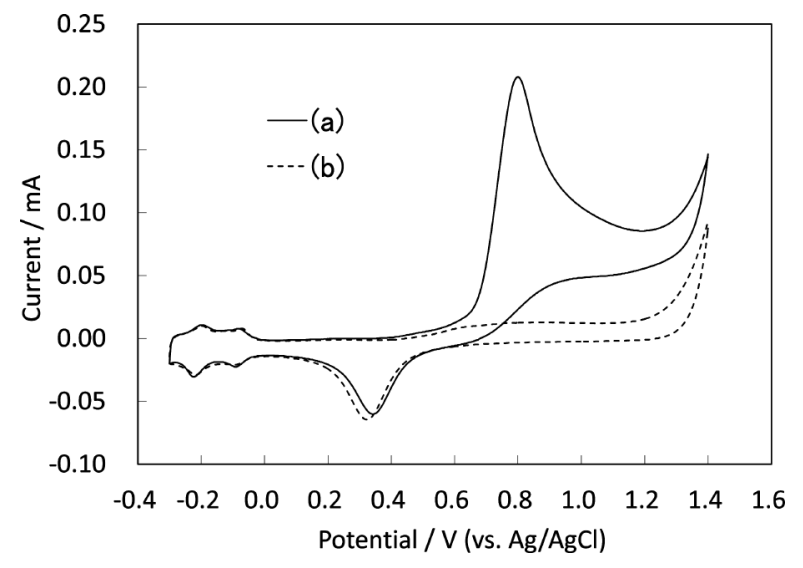

Fig. 1 Cyclic voltammograms of NF-GC electrode in a $0.1 \mathrm{M}$ phosphate buffer solution ( $\mathrm{pH} 2.1$ ) with $10 \mathrm{mM}$ sodium oxalate (a) and without sodium oxalate (b). Scan rate, $50 \mathrm{mV} / \mathrm{s}$.

\section{Experimental}

\section{Reagents and materials}

All chemicals were of analytical reagent grade, and used as received without any further purification. Sulfuric acid $\left(\mathrm{H}_{2} \mathrm{SO}_{4}\right)$ and sodium oxalate (sodium salt of oxalic acid) were supplied by Wako Pure Chemical Industries, Ltd. (Osaka, Japan). Ammonium carbamate was purchased from Merck (Germany). Aqueous solutions were prepared with deionized water. The GC electrode (3 mm diameter) was obtained from BAS Co., Ltd. (Tokyo, Japan). The supporting solution was a $0.1 \mathrm{M}$ phosphate buffer (pH 2.1)

\section{Preparation of an NF-GC electrode}

A potentiostat/galvanostat (HA-151B, Hokuto Denko Co., Ltd., Japan) was used to perform a constant potential electrolysis. An aqueous $\mathrm{Ag} / \mathrm{AgCl}$ ( $3 \mathrm{M} \mathrm{NaCl}$ electrolyte) electrode and a platinum wire were used as a reference and a counter electrode, respectively. The NF-GC electrode was prepared by stepwise electrolysis as follows. First, the GC electrode was electrooxidized in an ammonium carbamate aqueous solution at $+1.1 \mathrm{~V}$ (vs. $\mathrm{Ag} / \mathrm{AgCl}$ ) for $60 \mathrm{~min}$. Next, the electrooxidized GC electrode was electroreduced in $1.0 \mathrm{M}$ sulfuric acid at $-1.0 \mathrm{~V}$ (vs. $\mathrm{Ag} / \mathrm{AgCl}$ ) for $20 \mathrm{~h}$ at room temperature.

\section{Apparatus}

Electrochemical measurements were carried out using an automation polarization system (HZ-3000, Hokuto Denko, Tokyo, Japan) with a three-electrode cell consisting of a working glassy carbon electrode, an $\mathrm{Ag} / \mathrm{AgCl}(3 \mathrm{M} \mathrm{NaCl}$ electrolyte) reference electrode, and a $\mathrm{Pt}$ counter electrode. Voltammetric measurements of the sodium oxalate were carried out by using a GC electrode activated by the electrolytic-oxidation/reduction processes described above.

\section{Results and Discussion}

We evaluated the electrocatalytic activity of an NF-GC electrode with respect to the electrode reaction of oxalic acid. Figure 1 shows cyclic voltammograms (CVs) obtained when using an NF-GC electrode in $0.1 \mathrm{M}$ phosphate buffer electrolyte ( $\mathrm{pH} 2.1)$ with or without $10 \mathrm{mM}$ sodium oxalate. In the case of a CV

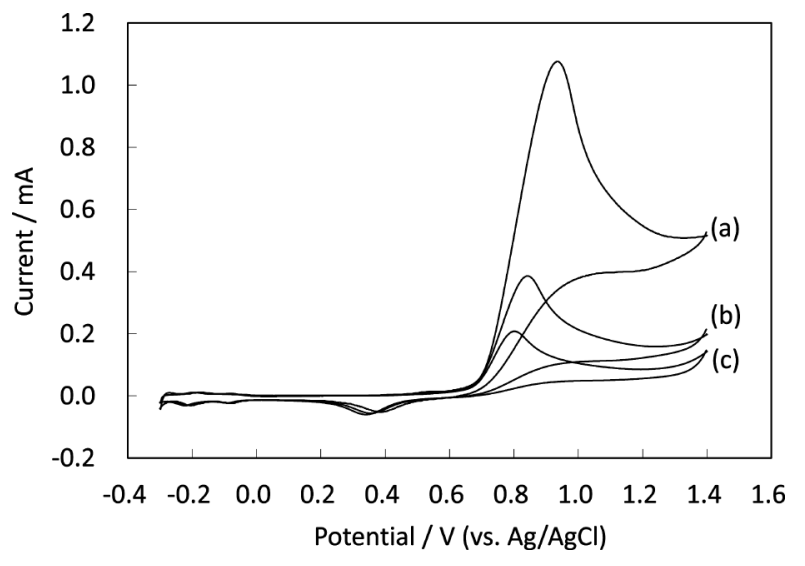

Fig. 2 Cyclic voltammograms of sodium oxalate at different concentrations in a $0.1 \mathrm{M}$ phosphate buffer solution $(\mathrm{pH} 2.1)$ obtained by NF-GC electrode. The sodium oxalate concentrations are $50 \mathrm{mM}$ (a), $20 \mathrm{mM}$ (b) and $10 \mathrm{mM}$ (c). Scan rate, $50 \mathrm{mV} / \mathrm{s}$.

measurement of the electrolyte containing $10 \mathrm{mM}$ sodium oxalate, an oxidation wave with a peak potential of $+0.8 \mathrm{~V}$ ( $\mathrm{vs}$. $\mathrm{Ag} / \mathrm{AgCl}$ ) was observed (Fig. 1(a)). In contrast, a cyclic voltammogram of electrolyte without sodium oxalate using the NF-GC electrode is shown in Fig. 1(b), and the small and broad oxidation wave with a dominant peak at approximately $+0.8 \mathrm{~V}$ (vs. $\mathrm{Ag} / \mathrm{AgCl}$ ) was measured. The potential of this small oxidation wave corresponds to that of the oxidation of oxalic acid obtained by the NF-GC electrode. This behavior obtained by the NF-GC electrode is regarded as a typical electrocatalytic oxidation of oxalic acid. This fact indicates that the groups introduced to the GC surface by electrolytic-oxidation/reduction processes function as electron-transfer mediators for the electrocatalytic oxidation of oxalic acid. We previously reported that there is a possibility for the formation of $\mathrm{N}$-containing functional groups (i.e., primary amine and hydrazino group) on a GC electrode surface fabricated by electrolytic modification in an ammonium carbamate aqueous solution and hydrochloric acid from results obtained by X-ray photoelectron spectroscopy. ${ }^{18}$ The hydrazino group is electro-oxidized to a diazo group via diazene (azo group), and these electroactive species are considered to function as electron-transfer mediators of the oxidation reaction of oxalic acid.

Figure 2 shows CVs of the electrocatalytic oxidation of oxalic acid at various concentrations $(10-50 \mathrm{mM})$ in a $0.1 \mathrm{M}$ phosphate buffer ( $\mathrm{pH} 2.1$ ) using the NF-GC electrode. The peak height of the oxidation wave of oxalic acid was actually increased with an increase in the concentration of oxalic acid. The CVs show that a well-defined oxidation peak of oxalic acid appears at $+0.8 \mathrm{~V}(v s . \mathrm{Ag} / \mathrm{AgCl})$ and it has been confirmed that the oxidation wave of oxalic acid obtained by the NF-GC electrode is located at a lower potential region, by approximately $500 \mathrm{mV}$, compared with that obtained by BDD electrodes under the same experimental conditions. ${ }^{7}$ For each $\mathrm{CV}$, the peak height of the reduction wave observed at $+0.35 \mathrm{~V}(v s . \mathrm{Ag} / \mathrm{AgCl})$ was unchanged when the potential was scanned in the cathodic direction from $+1.4 \mathrm{~V}$ (vs. $\mathrm{Ag} / \mathrm{AgCl})$. This indicates that this reduction wave is independent of the oxidation product of oxalic acid and electroinactive product must be produced by the electrode oxidation of oxalic acid. Then, the next electrode reaction of oxalic acid has been expected as Eq. (1).

$(\mathrm{COOH})_{2} \longrightarrow 2 \mathrm{CO}_{2}+2 \mathrm{H}^{+}+2 \mathrm{e}^{-}$ 


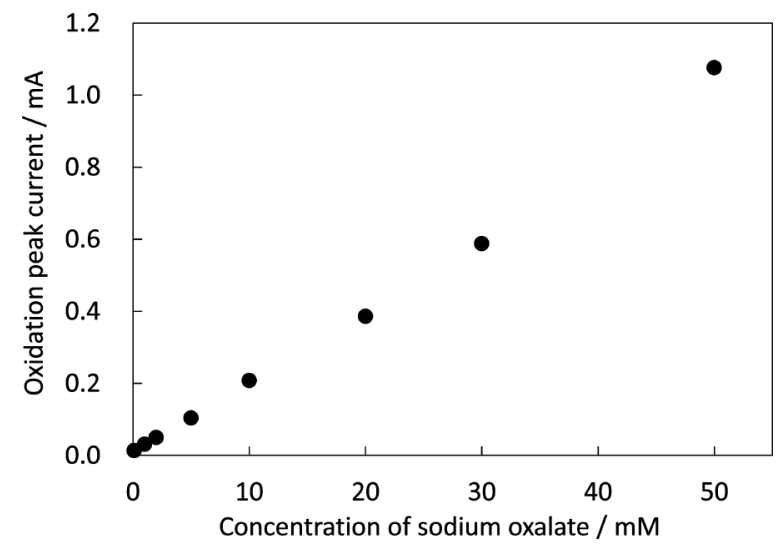

Fig. 3 Linear relationship between the concentration of sodium oxalate and the oxidation peak current obtained by NF-GC electrode. The scan rate of the $\mathrm{CV}$ experiments for measuring the oxidation peak current is $50 \mathrm{mV} / \mathrm{s}$.

The peak height for the oxidation wave of oxalic acid decreased when the $\mathrm{pH}$ of the electrolyte was greater than 6.0. This result means that the electrocatalytic activity for the active site of oxalic acid is significantly influenced by the $\mathrm{pH}$ of the electrolyte. The $\mathrm{pH}$-dependent studies of the electrocatalytic activity are now in progress.

Figure 3 shows a calibration curve for sodium oxalate on the NF-GC electrode obtained by using cyclic voltammetric measurements. The oxidation peak current was proportional to the sodium oxalate concentration in the range up to $50 \mathrm{mM}$ with a good correlation coefficient of 0.996 . The lower detection limit was found to be $0.1 \mathrm{mM}$.

Figure 4 shows cyclic voltammograms of a bare GC (a), NF-GC (b) and Pt bulk (c) electrodes in a $0.1 \mathrm{M}$ phosphate buffer solution ( $\mathrm{pH} 2.1)$ containing $10 \mathrm{mM}$ sodium oxalate. The highest electrocatalytic current can be measured at the NF-GC electrode among these electrodes. The peak potential of oxalic acid oxidation at the NF-GC electrode is at $+0.8 \mathrm{~V}$ ( $v s$. $\mathrm{Ag} / \mathrm{AgCl}$ ), which is lower than that at the bare GC electrode $(+1.3 \mathrm{~V})$ and Pt electrode (+0.95 V) under the same experimental conditions. This fact indicates that the NF-GC electrode is superior to the conventional electrodes concerning the electrode oxidation of oxalic acid.

\section{Conclusions}

We succeeded to prepare $\mathrm{N}$-containing functional groups introduced to a glassy carbon (NF-GC) electrode by stepwise electrolysis. NF-GC electrodes have been successfully demonstrated to be able to exhibit an excellent electrocatalytic oxidation wave of oxalic acid in an acidic medium. The NF-GC electrodes are found to be suitable for the electro-oxidation of oxalic acid, which is oxidized at a lower potential than at a $\mathrm{Pt}$ bulk and bare GC electrodes. We also have succeeded in the voltammetric detection of oxalic acid in the concentration range from 0.1 to $50 \mathrm{mM}$ by using an NF-GC electrode.

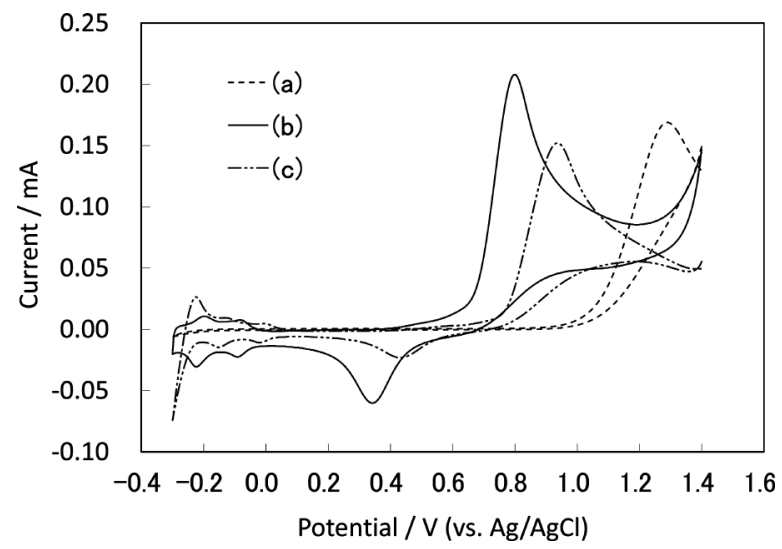

Fig. 4 Comparison of the CV obtained by bare GC (a), NF-GC (b) and Pt bulk (c) electrodes in a 0.1 M phosphate buffer solution ( $\mathrm{pH}$ 2.1) containing $10 \mathrm{mM}$ sodium oxalate. Scan rate, $50 \mathrm{mV} / \mathrm{s}$.

\section{References}

1. M. F. Laker, A. F. Hofman, and B. J. D. Meeuse, Clin. Chem., 1980, 26, 827.

2. C. W. Wilson, P. E. Shaw, and R. J. Knight, J. Agric. Food Chem., 1982, 30, 1106.

3. S. M. Reddy, S. P. Higson, and P. M. Vadgama, Anal. Chim. Acta, 1997, 343, 59.

4. A. Berna, A. Rodes, and J. M. Feliu, J. Electroanal. Chem., 2004, 563, 49.

5. S. N. Pron'kin, O. A. Petrii, G. A. Tsirkina, and D. J. Schiffrin, J. Electroanal. Chem., 2000, 480, 112.

6. C. A. Martinez-Huitle, S. Ferro, and A. De Battisti, Electrochim. Acta, 2004, 49, 4027.

7. T. A. Ivandini, T. N. Rao, A. Fujishima, and Y. Einaga, Anal. Chem., 2006, 78, 3467.

8. I. G. Casella, Electrochim. Acta, 1999, 44, 3353.

9. G. M. Jenkins and K. Kawamura, Nature, 1971, 231, 175.

10. O. Niwa, Bull. Chem. Soc. Jpn., 2005, 78, 559.

11. R. L. McCreery, Chem. Rev., 2008, 108, 2646.

12. R. W. Murray, "Electroanalytical Chemistry", ed. A. J. Bard, 1984, Vol. 13, Marcel Dekker, New York, 191.

13. R. L. McCreery, "Electroanalytical Chemistry", ed. A. J. Bard, 1991, Vol. 17, Marcel Dekker, New York, 221.

14. S. M. Lyth, Y. Nabae, S. Morita, S. Kuroki, M. Kakimoto, J. Ozaki, and S. Miyata, J. Phys. Chem. C, 2009, 113, 20148.

15. H. Watanabe, H. Yamazaki, X. Wang, and S. Uchiyama, Electrochim. Acta, 2009, 54, 1362.

16. S. Uchiyama, H. Watanabe, H. Yamazaki, A. Kanazawa, H. Hamana, and Y. Okabe, J. Electrochem. Soc., 2007, 154, F31.

17. A. Kanazawa, T. Okajima, S. Uchiyama, A. Kawauchi, and T. Osaka, Langmuir, 2014, 30, 5297.

18. S. Uchiyama, H. Matsuura, and Y. Yamawaki, Electrochim. Acta, 2013, 88, 251.

19. H. Matsuura, Y. Yamawaki, K. Sasaki, and S. Uchiyama, J. Environ. Sci., 2013, 25, 1077. 